\title{
Editorial
}

\section{Innovative Praxis and Theory Deficit: Formalization vs. Privatization in the Area of Conflict Resolution}

This second issue of the new CritQ is a conflict-ridden one! After all, the current and depending on your position - expanding or shrinking, but definitely globalizing world offers up more than enough conflicts. Legal instruments are not seldom seen as inadequate for solving them. Administrative processes in the state agencies and courts no longer seem to be the most efficient method for finding permanent solutions acceptable to all parties when it comes to disputes about the realization of major plans such as the expansion of train stations, airport operations, or the expansion of power grids, the effects of which can be felt both locally and nationwide. Arbitration processes and referenda are elements of democratic decision-making that might lead to better and faster results in these cases. Criminal justice and civil law are also being confronted with alternative solutions - whether they are called deals, adjudication, or mediation - for conflict resolution which come from innovative legal praxis and expand on or even depart from traditional, normed processes. But even these kinds of alternatives are not free of problems, particularly in regards to the rule of law or legal enforceability. Accordant reactions in (legal) policy, specifically from the legislature, as they are manifested in the EU mediation directive and its implementation in the member states are thus a logical consequence. Privatizing and formalizing tendencies are hereby juxtaposed with a dynamic structure and often mutually refer to one another. The way in which changes are made in this structure is often seen as being insufficient, not least as regards their theoretical underpinnings.

Since the beginning of 2012, this deficit is being countered by the research focus "Extrajudicial and Judicial Conflict Resolution" in Frankfurt am Main (www.konfliktloesung.eu), which is supported by the Johann Wolfgang Goethe-University, the Max-Planck-Institute for European Legal History (MPIeR), the University of Applied Sciences Frankfurt am Main, and, as an associate partner, the Society for Imperial Chamber Court Research (Wetzlar), and is being funded with the total of EUR 3.4 million for three years in the framework of the Sate of Hessen's Offensive for the Development of Scientific and Economic Excellence (Landes-Offensive zur Entwicklung Wissenschaftlich-ökonomischer Exzellenz - LOEWE). On the basis of a polychronic, legal-comparative approach and combination of legal history, legal science, history, and sinology, forms of conflict manifestation and conflict resolution are analyzed in a historical-empirical way in order to generate structural knowledge. To make this knowledge directly accessible to societal discourse, an expert commission of practitioners of judicial and extrajudicial dispute settlement acts as an innovative instrument for the academic-societal transfer of knowledge.

This is a good reason for the CritQ to dedicate at least part of its attention to the activities of the Frankfurt LOEWE researchers: How well the communication between academia and the praxis can work within a theoretical frame of reference was shown in 
a workshop with this research concentration, organized last February by Peter Collin from the MPIeR with the title "Arbitrating and Judging. Differentiation and Hybridization." Four of the contributions to this issue come from this event: Martin Engel, academic assistant at the LMU in Munich, describes quality criteria and model conceptions consensually, that is, based on the cooperation of the parties to the conflict and their lawyers in regard to the question of the requirement and extent of state regulation of conflict resolution. His answer recommends restraint in the face of the ambitious model of a "multi-door courthouse" in favor of quality assurance of legal advice based on economic incentives. For Karl Härter (MPIeR), professor at the TU in Darmstadt, infrajustice as a concept in historical criminological research does not yet represent a completely consistent theoretical model, but it could help to modify and specify the result-oriented term conflict resolution in favor of conflict management or conflict regulation and to overcome the reduction of the alternative dichotomy "judicial and extrajudicial." Patrick Schroeder, lawyer and economic mediator in Frankfurt am Main, looks at arbitration as a counterpart to state courts. The attestation of an efficient, now sometimes preferred alternative to conflict resultion, which he gives to arbitration, does not lessen the requirement to adapt to the changing needs of the users of arbitration services.

Three further contributions in this issue derive not from the LOEWE context, but that doesn't mean that their contents are any less cause for conflict: Sarah HennebergerSudjana and Fred Henneberger from the Research Institute for Labour Economics and Labour Law at the University of St. Gallen compare current developments in strike laws in Switzerland and Germany. Their comparison with the respective legal reality leads to the call for law-makers to take action, just as does the analysis from Anja Schiemann, adjunct professor and lawyer in Frankfurt am Main, of the rights of the accused in current criminal procedural law in comparison to the legal position of victims in proceedings. The same petition is made by Halina Wazyniak, German MP, in regard to the right of prisoners to internet access, the regulation of which remains incomplete and insufficient in the states' laws and implementation in the wake of the federalism reform. An academic-historical edited book marking the $200^{\text {th }}$ anniversary of the founding of the Humboldt University in Berlin offers a look at the history of the not-too-few conflicts of the university's Department of Law, reviewed for the CritQ by Yorick Wirth, academic assistant in the LOEWE focus "extrajudicial and judicial conflict resolution."

Just as with an editorial, historical research and research which focuses on the present remain incomplete without a look into the future: This year's 21st (!) Frankfurt Day of Legal Policy, held by Goethe-University's Department of Law in cooperation with the Hessian Ministry of Justice, for Integration and Europe, is also devoted to alternative forms of arbitration and conflict resolution - we therefore would like to warmly recommend this event on November 27, 2012, to you, our readers with a critically-reflective heart that beats for Europe! 